\title{
Performance Measurements on Active Cold Loads for Radiometer Calibration
}

Skou, Niels; Søbjærg, Sten Schmidl; Balling, Jan E.

\section{Published in:}

IGARSS: 2007 IEEE INTERNATIONAL GEOSCIENCE AND REMOTE SENSING SYMPOSIUM

Link to article, DOI:

10.1109/IGARSS.2007.4423333

Publication date:

2007

Document Version

Publisher's PDF, also known as Version of record

Link back to DTU Orbit

Citation (APA):

Skou, N., Søbjærg, S. S., \& Balling, J. E. (2007). Performance Measurements on Active Cold Loads for Radiometer Calibration. In IGARSS: 2007 IEEE INTERNATIONAL GEOSCIENCE AND REMOTE SENSING SYMPOSIUM: SENSING AND UNDERSTANDING OUR PLANET (pp. 2431-2434). IEEE. https://doi.org/10.1109/IGARSS.2007.4423333

\section{General rights}

Copyright and moral rights for the publications made accessible in the public portal are retained by the authors and/or other copyright owners and it is a condition of accessing publications that users recognise and abide by the legal requirements associated with these rights.

- Users may download and print one copy of any publication from the public portal for the purpose of private study or research.

- You may not further distribute the material or use it for any profit-making activity or commercial gain

- You may freely distribute the URL identifying the publication in the public portal 


\title{
Performance Measurements on Active Cold Loads for Radiometer Calibration
}

\author{
Niels Skou, Sten S. Søbjærg, and Jan Balling \\ Danish National Space Center, B 348 \\ Technical University of Denmark \\ DK 2800 Lyngby, Denmark \\ ns@spacecenter.dk
}

\begin{abstract}
Two semi-conductor Active Cold Loads (ACLs) to be used as cold references in spaceborne microwave radiometers have been developed. An X-band frequency has been chosen, and the target noise temperature value is in the 50 to $100 \mathrm{~K}$ range. The ACLs are to be characterized in the operating temperature range $0-50{ }^{\circ} \mathrm{C}$, and long term stability must be assessed. To this end a Test Bed has been developed. This Test Bed is actually a stable radiometer, and its design and development is discussed. The test setup is described, and preliminary test campaign results indicate output temperatures of $73 \mathrm{~K}$ and $51 \mathrm{~K}$ for the two ACLs. The temperature sensitivity is slightly below $0.4 \mathrm{~K} /{ }^{\circ} \mathrm{C}$ for the units, and excellent stability seems to prevail.
\end{abstract}

Keywords; microwave, radiometer, calibration, active cold load

\section{INTRODUCTION}

A transistor based cold load for radiometer calibration, a socalled active cold load (ACL), is being developed for future space programs.

Typically, a radiometer needs frequent calibration using a hot and a cold reference point. Ideally these references should encompass the radiometer's expected range of input brightness temperatures - typically some 100 to $300 \mathrm{~K}$ for an Earth sensing system. The hot reference presents little problem and can just be a microwave load at the internal instrument temperature. Cooling a load to below $100 \mathrm{~K}$ in space is not easy, and therefore a view to free space (around $3 \mathrm{~K}$ ), either via a special sky viewing antenna or via a reflector in front of the main feed horn, has typically been applied [1]. But this is not always very practical, hence the desire for a small, low power, low weight, stable cold reference.

Two such ACLs - based on transistors connected backwards, i.e. the gate is connected to the output connector have been designed and built by Ylinen Electronics, and their performance is being assessed at the Technical University of Denmark. For this first test development a frequency in the Xband has been chosen.

The overall objective of the present work is to design and construct a Test Bed for monitoring the ACLs, and to carry out tests of their performance. The specific objective of this paper is to describe the detailed design of the Test Bed, outline the test set-up, and report on preliminary test results.

\section{SPECIFICATIONS AND REQUIREMENTS}

Based on preliminary considerations, the following set of specifications was worked out as a starting point for the development.

ACL:

- frequency: $10.69 \mathrm{GHz} \pm$ at least $50 \mathrm{MHz}$

- noise temperature below $150 \mathrm{~K}$ - possibly down to $50 \mathrm{~K}$

- nominal operating temperature is $25^{\circ} \mathrm{C}$

- RF interface: coaxial - SMA

- the ACL shall be characterized in the temperature range $0-50{ }^{\circ} \mathrm{C}$

Test Bed:

- frequency: $10.69 \mathrm{GHz} \pm 50 \mathrm{MHz}$

- absolute accuracy: $\pm 1 \mathrm{~K}$ (goal: $\pm 0.6 \mathrm{~K}$ )

- $\quad$ stability better than $\pm 0.1 \mathrm{~K}$ over $5 \mathrm{~min}$

- $\quad$ sensitivity better than $0.1 \mathrm{~K} @ 5 \mathrm{sec}$ integration

- integration time: $0.1-10 \mathrm{sec}$

- 2 ACL inputs

- input reflection coefficient $-30 \mathrm{~dB}$ (target)

- the Test Bed system must record the ACL temperature to better than $0.5^{\circ} \mathrm{C}$ with $0.05^{\circ} \mathrm{C}$ resolution

- the Test Bed system must record ACL bias voltages and currents

- all ACL parameters recorded each $5 \mathrm{sec}$

Concerning the test campaign, a characterization of the ACLs in the temperature range of 0 to $50{ }^{\circ} \mathrm{C}$ is to be followed by a long-term (around one year) stability test.

\section{TEST BED DESIGN}

The output of the ACL is expected to be in the $60-100 \mathrm{~K}$ range, and it has to be measured to within $1 \mathrm{~K}$. It is hoped that the drift of the ACL is below $1 \mathrm{~K}$ per year. The Test Bed is thus in fact a radiometer having an absolute accuracy of better than $1 \mathrm{~K}$. The best radiometer stability and accuracy arises if the noise temperature to be measured, here the ACL around 60 $100 \mathrm{~K}$, is close to the radiometers internal reference - or if the radiometer is often calibrated using a standard close to it. A

The described work was supported by the European Space Agency 
liquid nitrogen target (LN2) around $77 \mathrm{~K}$ would serve well for such a reference or calibration standard.

The long-term tests to be carried out using the Test Bed require continuous measurements of the ACL, and the Test Bed will be operated continuously. Thus a LN2 reference, which has to be attended to by personnel, is not practical - but absolutely viable as an external calibration standard. Measurement fidelity will thus be assured by stability of the Test Bed (including its internal references) in conjunction with this LN2 calibration to be carried out at certain intervals.

\section{A. Microwave Front End}

Two internal references are used: one termination at the temperature of the microwave front end, and one cooled by a Peltier element. Also, an internal noise diode that may be switched on and off is employed. The output of the noise diode - properly attenuated to somewhat below $100 \mathrm{~K}$ - is injected after the input switch and thus added to the signal from any source. This will enhance calibration fidelity, and make linearity check simple.

Following these considerations, the Test Bed block diagram looks like shown in Figure 1.

The Test Bed is a direct detect, total power radiometer with frequent calibration and $1 \mathrm{sec}$ integration time (the integration is in fact carried out in a computer and can be varied). The radiometer has a low loss switch at the input. This switch selects one of 3 external signals (ACLs or LN2 reference) or one of the two internal loads.

The external inputs are supplied with hi-quality isolators ensuring very low input reflection coefficients, and hence well defined working conditions for the ACLs. At the same time the noise temperature being emitted from the Test Bed towards the ACLs and the LN2 target is well defined and equal to the internal front end physical temperature. The 3 input signal paths are made as equal as possible in order to give good balance between the ACL signals and the primary calibration signal from the LN2 target.
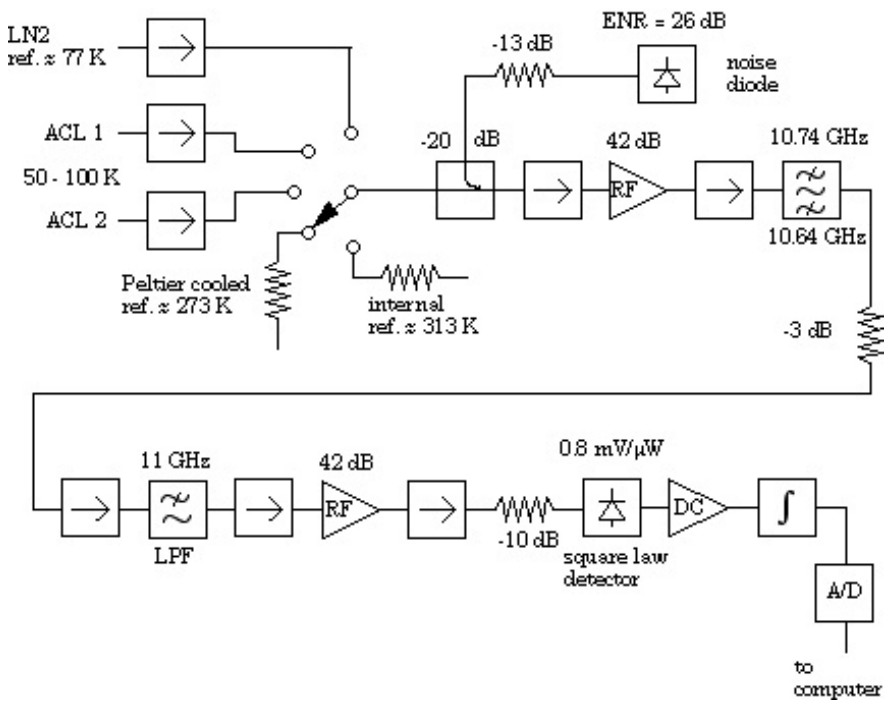

Figure 1. Block diagram
The square law detector is a tunnel diode detector being square law up to some $-20 \mathrm{dBm}$ input power level. Here it is assumed to operate with a $-24 \mathrm{~dB} d \mathrm{Bm}$ level in order to assure very good behavior. The noise figure of the radiometer is calculated to be $4.6 \mathrm{~dB}$, meaning that $\mathrm{T}_{\mathrm{N}}=546 \mathrm{~K}$. This corresponds to a sensitivity of $0.086 \mathrm{~K}$ for a $318 \mathrm{~K}$ input signal (hot load) and $1 \mathrm{sec}$ integration time.

\section{B. Input Switch}

The input switch could be a PIN switch or a rotary coax switch. The PIN switch features fast switching, endless number of switching operations, some loss, and moderate isolation. The coax rotary switch features moderate speed switching, limited number of operations, low loss, and very high isolation.

Switching speed is not of concern here as the potentially fastest operations correspond to $5 \mathrm{sec}$., and even a coax switch features 10-20 msec switching time typically.

The number of switching operations is an issue during a long term test. This is no problem for the PIN switch, but coax switches are typically guaranteed to sustain more than 1 million operations. A realistic scenario could be that calibration takes place each 5 minutes, i.e. the switch runs through its 5 positions each 5 minutes. This leads to around a half million operations per year. It is seen that the large number of operations favors the PIN switch option.

Loss is always of concern in radiometer input circuitry. The signal running through a lossy component is changed according to the following equation:

$$
\mathrm{T}_{\text {OUT }}=\mathrm{T}_{\mathrm{IN}} \cdot \mathrm{L}+(1-\mathrm{L}) \cdot \mathrm{T}_{0}
$$

where $\mathrm{T}_{\mathrm{IN}}=100 \mathrm{~K}$ and $\mathrm{T}_{0}=313 \mathrm{~K}$ in the present case. $\mathrm{A}$ PIN switch typically features $2 \mathrm{~dB}$ loss corresponding to $\mathrm{L}=$ 0.63 . Inserting these values results in $\mathrm{T}_{\text {OUT }}=179 \mathrm{~K}$ meaning that our signal has been increased by as much as $79 \mathrm{~K}$. This is in itself no problem provided that temperature and loss are constant and known. The loss is assumed constant. If the temperature is measured to within $0.3{ }^{\circ} \mathrm{C}$ this brings the uncertainty below $0.1 \mathrm{~K}$. A coax switch typically features 0.25 $\mathrm{dB}$ of loss resulting in a signal increase of $12 \mathrm{~K}$ in the present case. This is almost 7 times lower that for the PIN switch, and the requirements to loss and temperature stability are accordingly 7 times more relaxed. The loss issue favors the coax switch option.

The isolation in the switch is an important issue. The signal from the external LN2 calibration load is highly varying (from $77 \mathrm{~K}$ to some $298 \mathrm{~K}$ ) dependent on whether LN2 is present or not. This change of $221 \mathrm{~K}$ will leak into the other switch inputs and give an uncertainty of $2.2 \mathrm{~K}$ for $20 \mathrm{~dB}$ isolation, and $0.2 \mathrm{~K}$ uncertainty for $30 \mathrm{~dB}$ isolation. $30 \mathrm{~dB}$ isolation is a typical value for a PIN switch, while the coax switch typically features $60 \mathrm{~dB}$ isolation. Isolation issues favor the coax switch option.

Following such discussions, it was decided to opt for the coaxial rotary switch, due to its superior microwave properties. 


\section{Microwave Filter}

The primary filter comprises a metallic ladder inserted in a section of waveguide. Within the $3 \mathrm{~dB}$ bandwidth of $100 \mathrm{MHz}$ the return loss is below $25 \mathrm{~dB}$.

The filter has no spurious responses below the band pass, but it has significant responses in the $14-20 \mathrm{GHz}$ range. Modern hi-quality amplifiers and isolators are quite broadband devices: the actually selected amplifiers have almost nominal gain in the range $1-16 \mathrm{GHz}$, and the isolators operate over a 7 $-17 \mathrm{GHz}$ range. The contribution to the noise signal level on the detector from this wide band is a problem. Hence, the waveguide filter is augmented by a coaxial low-pass filter, having an $11 \mathrm{GHz}$ cut-off frequency, and an attenuation of 20 $\mathrm{dB}$ at $14 \mathrm{GHz}$.

\section{Control System and Data Recording}

The interface to the outside world is based on a so-called LIAB (Linux-In-A-Box) single board PC. The single-board PC is equipped with industry-standard interfaces such as Ethernet and RS232. The only external connection from the Test Bed system, is thus an RJ45 connector for the Ethernet.

Control and monitoring software which can run on any standard PC with an Ethernet connection has been developed. The software receives input from the user in the form of setup files (e.g. switch control schemes for the calibration schedule) and real-time commands, and it is also capable of displaying system status and output data in real time.

Data can be stored on the same or on any other computer connected to the network, and the transfer is carried out automatically by the Linux single board computer, using standard FTP.

\section{E. Temperature Stabilized Enclosure}

The microwave - and thus temperature sensitive components are mounted in a carefully temperature regulated box, and additionally all vital components are temperature monitored by the control- and data recording system. The highly insulated inner enclosure, housing the microwave components, is an aluminum box, covered by a foam layer with a thickness of $10-20 \mathrm{~mm}$ on all sides. The components are mounted on a separate platform, an $8 \mathrm{~mm}$ aluminum plate, inside the box, and the platform is kept thermally de-coupled from the box, as it is carried by plastic supports.

The inner box is placed inside the 19" outer box, holding the remaining components, and again the direct heat conductivity is limited through the use of plastic supports. The only heat flow from the inner box to the outside world is hence through the air, circulating in the outer box, driven by the internal fan, shown in Figure 2. The circulating air is also temperature stabilized, and this is ensured by variable air exchange to/from the outside world, regulated by the variable fan, shown in the lower left corner of Figure 2.

The design of the thermal control is based on two independent, digital PI-regulators. One takes care of the heating of the microwave section, and the other controls the variable speed fan. The described system has proven a thermal stability of the front end to better than $0.02{ }^{\circ} \mathrm{C}$ for a $15^{\circ} \mathrm{C}$ change in ambient temperature.

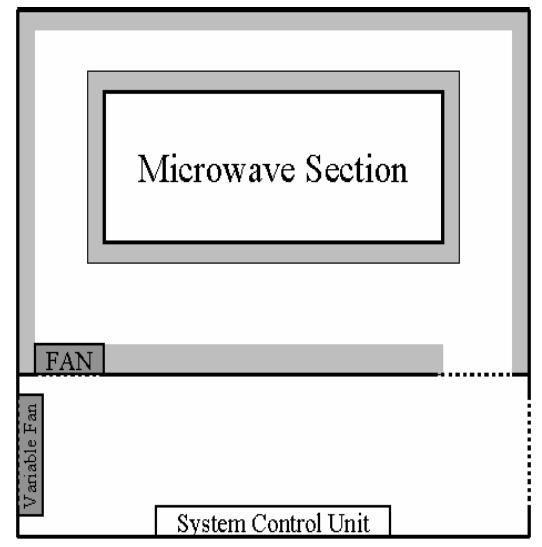

Figure 2. Temperature stabilized enclosure

\section{LIQUID NITROGEN TARGET}

The target used for absolute calibration is a microwave absorber in a stainless steel bucket insolated by styrofoam. A standard antenna horn views this target, see Figure 3. For calibration liquid nitrogen is poured into the bucket, it is ensured that the absorber tips are covered, and a metal lid covering the opening around the antenna horn is put in place.

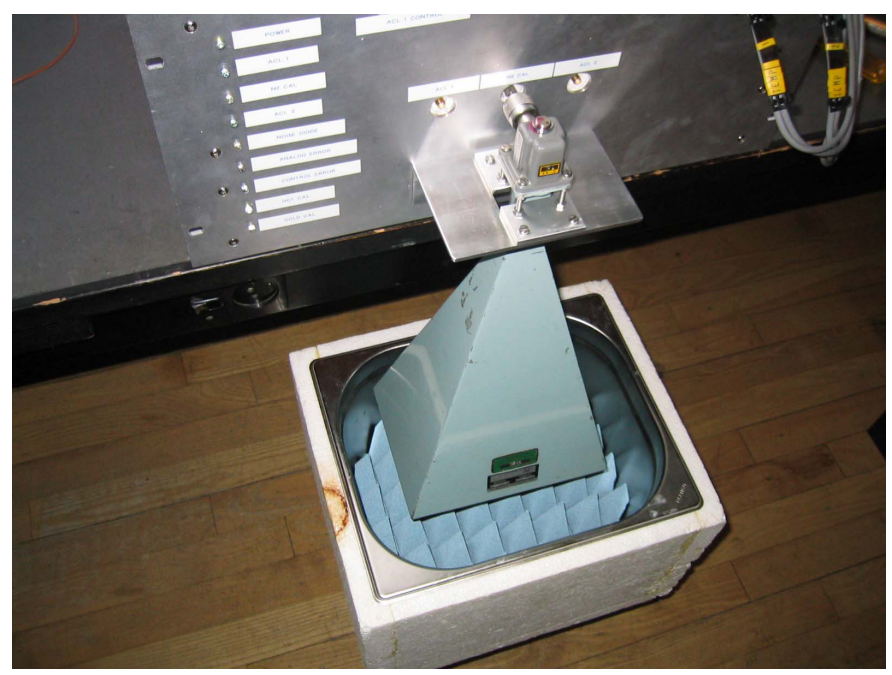

Figure 3. Calibration target (without lid)

The loss in the system is of paramount importance for the absolute calibration. The antenna horn is practically lossless but the coax-to-waveguide adapter (including a small section of antenna waveguide) is lossy. This loss is very difficult to measure accurately due to the mix of coax and waveguide.

The loss has been assessed in 2 different ways using a network analyzer: (1) measuring the return loss on the short circuited adapter and divide by 2 results in $0.14 \mathrm{~dB}$ loss; (2) measuring the transmission loss on 2 identical adapters mounted back-to-back and divide by 2 results in $0.20 \mathrm{~dB}$ loss. Using again equation (1) with $\mathrm{T}_{\mathrm{IN}}=77 \mathrm{~K}$ and $\mathrm{T}_{0}=293 \mathrm{~K}$ results in an increased brightness temperature of $6.3 \mathrm{~K}$ and 9.7 
$\mathrm{K}$ respectively. This corresponds to $\mathrm{a} \pm 1.7 \mathrm{~K}$ uncertainty, and the required $\pm 1 \mathrm{~K}$ absolute accuracy cannot be assured presently. This awaits more delicate loss measurements. Note that concerning stability this is not a problem as the adapter temperature is quite constant and monitored by the Test Bed.

\section{THE TEST CAMPAigN}

Two major stages are foreseen in the test activities: a relative short campaign in which the Test Bed measures the output of the ACLs under varying physical temperature conditions, and a long term (around 1 year) stability test in which the output of the ACLs are monitored continuously by the Test Bed under ambient temperature conditions.

The varying temperature campaign can be described a bit further as containing a staircase scheme in which the temperature is increased from $0^{\circ} \mathrm{C}$ to $50^{\circ} \mathrm{C}$ in $10^{\circ} \mathrm{C}$ steps, and an oscillating scheme in which the temperature is varied quasisinusoidally around ambient with a $5{ }^{\circ} \mathrm{C}$ amplitude. During this test the ACLs are separated from the Test Bed by $80 \mathrm{~mm}$ long stainless steel, semi rigid (0.087') coax cables in order to have the ACLs inside a climate test chamber and the Test Bed outside. The loss in these coax lines are corrected for. The measurements show that the output of the ACLs increase linearly with physical temperature with a sensitivity of $0.38 \mathrm{~K} /$ ${ }^{\circ} \mathrm{C}$ for $\mathrm{ACL} 1$ and $0.35 \mathrm{~K} /{ }^{\circ} \mathrm{C}$ for ACL2.

During the long term stability test the Test Bed and the ACLs are left undisturbed in a quiet basement room. The ACLs are not temperature regulated, but will just be at ambient (typically $21^{\circ} \mathrm{C}$ ). The ACLs are connected directly to the Test Bed (no extra transmission lines), see Figure 4.

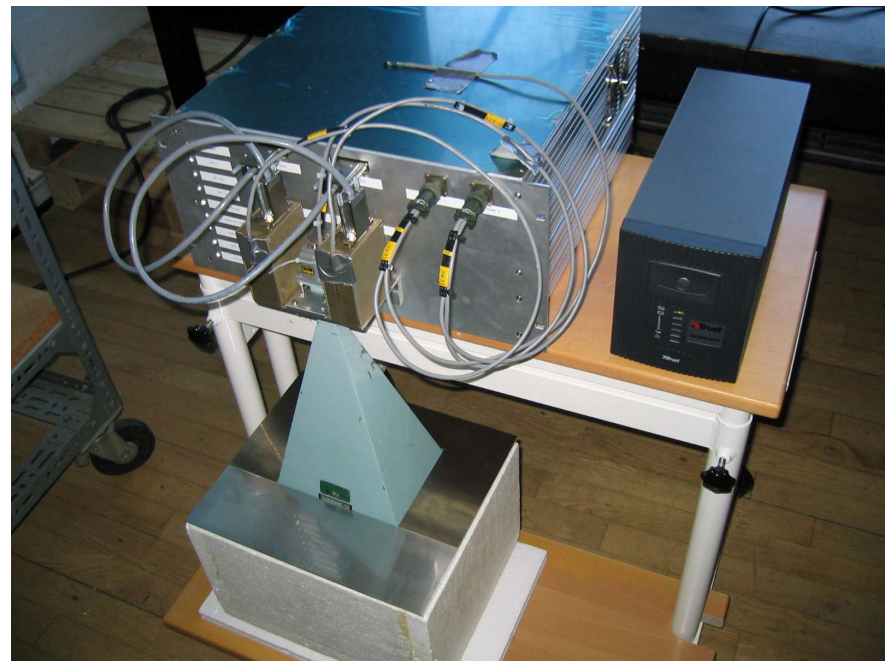

Figure 4. Long term stability set-up

The 3 input connectors of the Test Bed are side by side on the front plate (see also Figure 3). The ACLs are the two metal boxes seen on either side of the calibration horn. In Figure 4 the calibration target is properly covered by its metal lid. The measurements rely on stability and internal calibration of the Test Bed, augmented by LN2 calibrations at suitable intervals. During the stability tests a 12 minutes cycle, in which the
ACLs are measured alternatively for 5 min. interrupted by 1 min. internal calibration, is used. The validity of this scheme is supported by actual measurements of the Test Bed stability, see Figure 5. The standard deviation of the output is calculated for increasing integration when measuring the internal load, and it is seen to be well below $0.1 \mathrm{~K}$ up to more than 6 mins, i.e. the time between calibrations.

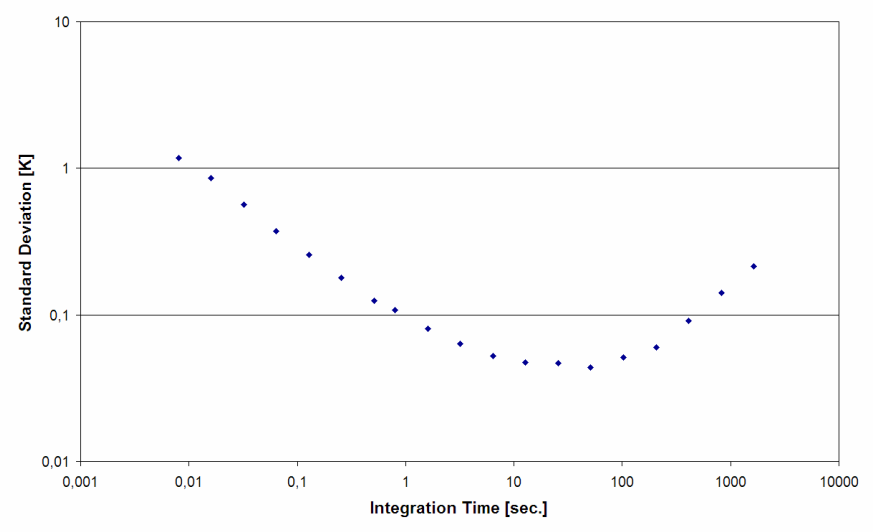

Figure 5. Test Bed Std. Dev. vs. integration time

The first LN2 calibration reveals that the output of ACL1 is $73 \mathrm{~K}$ and of ACL2 $51 \mathrm{~K}$. The first month of operation indicates no drift in the ACL outputs, but this is a very preliminary result. Assessment of the (small) drift requires long time series and careful analysis to come in due time as the experiment goes on.

\section{CONCLUSIONS}

Transistor based active cold loads for calibration seems to be a viable option for future radiometer systems - even in space. Two X-band experimental ACLs have been designed and manufactured. Likewise a Test Bed has been developed with the aim of characterizing the ACLs, both concerning thermal behavior and long-term stability. Measurements indicate that the ACLs provide a stable, cold noise temperature of $73 \mathrm{~K}$ and $51 \mathrm{~K}$ respectively, and that the dependence on physical temperature is around $0.4 \mathrm{~K} /{ }^{\circ} \mathrm{C}$. The measurement campaign is ongoing at the time of writing, but excellent stability over time seems to prevail.

\section{ACKNOWLEDGMENT}

The development of the Test Bed was supported through fruitful discussions with Mr. Janne Lahtinen and Mr. Petri Piironen. These gentlemen are herewith acknowledged.

\section{REFERENCES}

[1] N. Skou and D. LeVine, "Microwave Radiometer Systems: Design and Analysis", Artech House, 2006. 